\title{
Internal Carotid Artery Embolism by Shotgun Pellet
}

\author{
JITENDAR M. SETHI AND BOHDAN ROZDILSKY
}

SUMMARY: Various examples of foreign body embolization of cerebral arteries, usually followed by serious consequences, have been reported (Lindberg et al., 1961; Chason et al., 1963; Steele et al., 1972; Wetli et al., 1972). However, a shotgun pellet entering the left atrium of the heart through a gunshot wound of the chest with subsequent embolic occlusion of one of the carotid arteries appears to be unique. It is the subject of this short communication.

RESUME: L'embolisation d'artères cérébrales par des corps étrangers hétérogènes, suivie souvent de conséquences sérieuses, n'a que rarement été rapporté (Lindberg et al., 1961; Chason et al., 1963; Steele et al., 1972; Wetli et al., 1972). Nous rapportons un cas qui nous semble unique et inédit d'occlusion embolique d'une artère carotide par suite d'une blessure par coup de fusil du thorax avec pénétration d'une particule métallique dans l'oreillette gauche.

From the Division of Neuropathology, University of Saskatchewan, College of Medicine, Saskatoon, Saskatchewan.

Reprint requests to: Dr. Bohdan Rozdilsky, Division of Neuropathology, University of Saskatchewan, College of Medicine, Saskatoon, Saskatchewan, Canada S7N OWO.

\section{CASE REPORT}

A 27 year old North American Indian man, previously well, was shot accidently through the back with a resulting $3 \mathrm{~cm}$ wide entry wound over the left scapular region. Emergency treatment to combat the shock was applied and endotracheal intubation and chest drainage were provided. He was then transferred to the University Hospital in Saskatoon.

On examination his blood pressure was $90 / 70$, the pulse was $120 / \mathrm{min}$. and respirations $24 / \mathrm{min}$. Numerous rales were audible in both upper lung fields with pink frothy secretions being recovered by tracheal suction. There were no other external signs of injuries. Neurologically, he was disorientated but able to execute certain commands. No cranial nerve deficit was noted except for some weakness of the external rectus of the left eye. There was a slight weakness of the left upper extremity with increased biceps and triceps reflexes. Both lower limbs were flexed and no movement could be elicited in either of the lower limbs. No response to pin prick was noted from T4-5 downwards. Routine blood count and urinalysis disclosed normal values. An $x$-ray of the chest (Fig. 1) demonstrated a large number of metallic pellets in the posterior thoracic wall, around the entry wound, and towards the midline. Some were present in the dorsal part of the left lung. X-rays of skull (Fig. 2 \& 3 ) revealed one of the pellets located in the right parasellar region.

The patient was treated symptomatically with cerebral decongestants and wàs given respiratory support. The next morning his right pupil was enlarged and he was less responsive. Gradually, both pupils became fixed and dilated followed by right sided ophthalmaplegia and left upper limb paresis. He was unable to maintain oxygenation despite the controlled ven- tilation. EEG showed no electrical activity on two readings 24 hours apart and the patient was taken off the respirator on the fourth day after the accident.

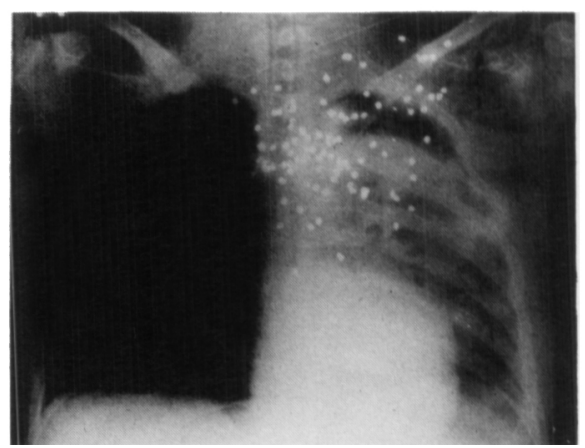

Fig. 1. Chest $\mathrm{x}$-ray showing numerous shotgun pellets in the chest wall and in the lung fields.

Postmortem examination revealed traumatic damage of the left lung, transection of the spinal cord at T3-4 level, and a $0.2 \mathrm{~cm}$ hole in the left myocardial atrium (Fig. 4) with only slight hemorrhage around it and no intrapericardial bleeding.

On opening the skull, no damage to the dura or cranium was noted. The right cerebral hemisphere was grossly swollen. No external traumatic lesion was evident. An x-ray of the brain disclosed a metallic fragment lodged in the right basal area. Dissection of the circle of Willis demonstrated a blockage of the lumen by the pellet at the bifurcation of the right internal carotid artery (Fig. 5). Histological section of the myocardium taken to include the level of perforation of the left atrial wall confirmed the antemortem nature of the lesion. Hemorrhagic suffusion and a recent imflammatory reaction were found. This was the site at which the pellet entered the systemic circulation. There was extensive recent ischemic necrosis of the left cerebral hemisphere 
associated with transtentorial herniation and secondary hemorrhages of the brain stem.

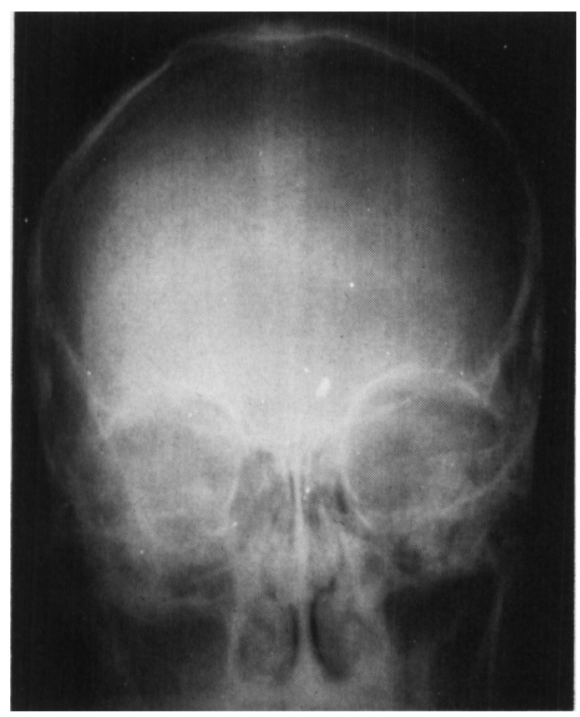

Fig. 2 and 3. A single pellet is seen in the cranial cavity. It was thought to be lodged in posterior hypothalamus.

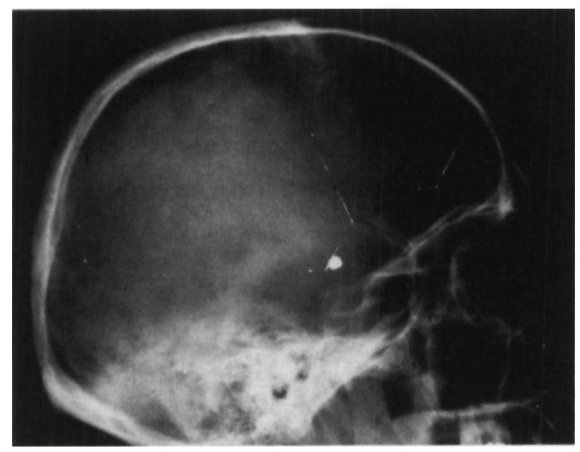

\section{DISCUSSION}

A variety of exogenous particulate materials of mineral or vegetable nature have been implicated in foreign body embolism of cerebral arteries (Ghatak, 1975). The circumstances under which the foreign material enters the circulation and produces cerebral embolization are varied and numerous. Occasionally, especially in pediatric

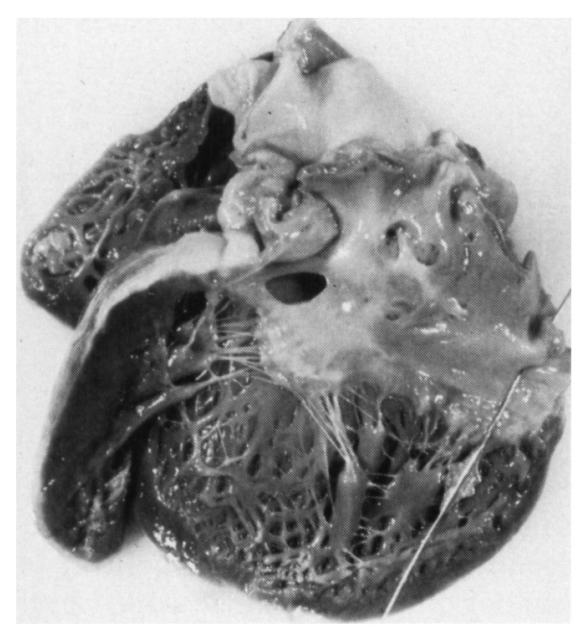

Fig. 4. Probe is inserted into the perforation of the left atrial wall through which the pellet entered the systemic circulation.

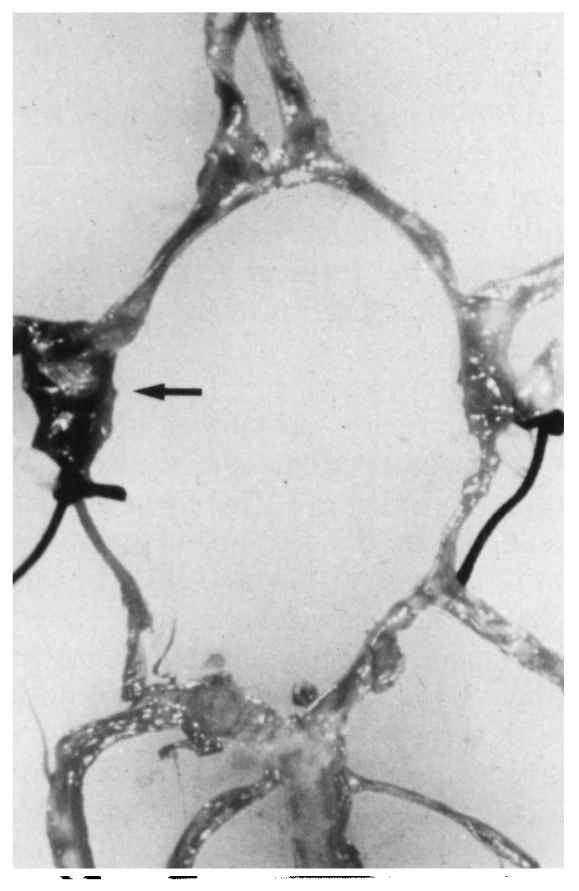

Fig. 5. Dissected blood vessels of the circle of Willis. Arrow indicates the site of impaction of pellet in the lumen of the right internal carotid artery. practice, the route of entry remains unexplained (Steele et al., 1972). The most common instances have been associated with cardiac surgery (Lindberg et al., 1961; Aguilar et al., 1971) and the use of a silicone defoaming agent, or were complications of $\mathrm{x}$ ray contrast studies (Chason et al., 1963). These complications of heart surgery have been largely eliminated with refinement of surgical techniques. Talc embolism has been described in drug addicts using talc containing oral tablets in suspension for intravenous injections (Wetli et al., 1972). In spite of the common occurrence of firearm accidents, a shot gun pellet embolism of cerebral arteries as reported here appears to be exceptional and not previously reported. A massive hemispheric infarction with compression of the brainstem was the immediate cause of death of the patient.

\section{REFERENCES}

AGUILAR, M. J., GERBODE, F. and HILL, J. D. (1971). Neuropathologic complications of cardiac surgery. J. Thorac. Cardiovasc. Surg. 61: 676-685.

CHASON, J. L., LANDERS, J. W. and SWANSON, R. E. (1963). Cotton fiber embolism. A frequent complication of cerebral angiography. Neurology 13:558-560.

GHATAK, N. R. (1975). Pathology of cerebral embolization caused by nonthrombotic agents. Human Path. 6: 599-610.

LINDBERG, D. A. B., LUCAS, F. V., SHEAGREN, J. and MALM, J. R. (1961). Silicone embolization during clinical and experimental heart surgery employing a bubble oxygenator. Am. J. Pathol. 39: 129-144.

STEELE, J. J., KILBURN, H. L., and LEECH, R. W. (1972). Phytotic (mycotic) intracranial aneurysm with an unusual pathogenesis. A case report. Pediatrics 50: 936-939.

WETLI, C. V., DAVIS, J. H. and BLACKBOURNE, B. D. (1972). Narcotic addiction in Dale County, Florida. An analysis of 100 consecutive autopsies. Arch. Pathol. 93: 330-343. 